\title{
Stuck at the Cross-Road: Intersectional Aspirations in the EU Anti-Discrimination Legal Framework
}

\author{
ANNICK MASSELOT \\ University of Canterbury \\ annick.masselot@canterbury.ac.nz
}

\author{
JESS BULLOCK \\ University of Canterbury \\ jess.bullock@gmail.com
}

\begin{abstract}
This paper seeks to critically assess the way the EU guarantees the protection of individuals who are discriminated on multiple grounds. As EU law does not recognise that multiple identities can intersect, it is argued that the current anti-discrimination legal framework is not adequate to deal with claims of multiple and intersectional discrimination. Recent legislative developments have, however, raised the issue of multiple discrimination and intersectional disadvantage but they remain guarded and often take a simplistic, rather than an intersectional approach. The EU anti-discrimination legal framework appears to be at a cross-road and choices made by the legislator to promote the concept of multiple discrimination over that of intersectional disadvantage will have profound consequences for the EU anti-discrimination legal framework as a whole and its future developments.
\end{abstract}

Key words: anti-discrimination; directive; identity; intersectionality; intersectional disadvantage; European Union law; multiple discrimination.

\section{Introduction}

Human beings have several identity markers attributable to their individual status, which include "an age, a gender, a sexual orientation and an ethnicity." Over time they might acquire, lose or change religion and/or they might develop a disability. Identities are not set in stone and are made up of multiple elements. Some identity markers are more permanent than others; age and some disabilities evolve with time, but most people will not change 
their sex. Individuals can decide to highlight some of their identities but not all traits are up for discretion; one can choose their religion, but not their age. A person can also, to an extent, control the visibility of certain aspects of their identity; sexuality can be hidden, while this is not necessarily the case for gender. ${ }^{2}$ The very nature of identities is therefore both complex and also fluid. Accordingly, the protection of individuals' identities demands an equally elaborate and adaptable anti-discrimination legal framework because if one is "to assume that groups are rigidly delineated by race, gender, disability, sexual orientation or other status, [then one] is to render invisible those that are found in the intersection between those groups." 3

This paper seeks to critically assess the way the EU guarantees the protection of individuals who are discriminated on multiple grounds. Prima facie, the EU has set a high standard. The values of the EU, enshrined in the Treaty on European Union (TEU), underline the importance of accommodating, protecting and fostering citizen's diversity in order to achieve both market unity and high standards of living. In Article 2, the TEU recalls that the Union is founded on "the values of respect for [...] equality [...] and [...] human rights, including the rights of persons belonging to minorities. These values are common to the Member States in a society in which pluralism, nondiscrimination, tolerance, justice, solidarity and equality between women and men prevail." The main tasks and activities of the EU are outlined under Article 3 TEU and include in paragraph 3 the combat of social exclusion and discrimination, as well as the promotion of "social justice and protection, equality between women and men, solidarity between generations and protection of the rights of the child." In addition, Article 6(1) TEU establishes that the rights, freedoms and principles set out in the Charter of Fundamental Rights of the EU (the Charter), 4 which reinforces the EU values with regard to equality and anti-discrimination, shall have the same legal value as the Treaties. Finally the Treaty on the Functioning of the European Union (TFEU) set down provisions regarding gender equality (Article 157 TFEU) and provides competence for the EU "to take appropriate action to combat discrimination based on sex, racial or ethnic origin, religion or belief, disability, age and sexual orientation" (Article 19 TFEU). These principles and values are further implemented and supported by an array of secondary legislation and non-legally binding (soft) provisions.

However, despite laying down strong commitments to equality and nondiscrimination, EU law almost exclusively addresses single axes of discrimination and the legislative instruments comprise exhaustive lists of prohibited grounds of discrimination. In other words, the legal framework does not appropriately address the situation of citizens who are discriminated against on a number of prohibited axes within that legal framework. For example, under EU law, a coloured skin lesbian who found herself being

\footnotetext{
2 J. Kantola and K. Nousianen, 'Institutionalizing Intersectionality in Europe: Introducing the Theme', International Feminist Journal of Politics, Vol.11, No. 4, 2009, p. 468.

3 S. Fredman, 'Positive Rights and Positive Duties; Addressing Intersectionality', in D. Schiek, and V. Chege (eds.), European Union Non Discrimination Law: Comparative Perspectives on Multidimensional Equality Law, Abingdon, Routledge-Cavendish, 2008, p. 73.

4 The Charter of Fundamental Rights of the European Union of 7 December 2000, as adapted at Strasbourg, on 12 December 2007.
} 
discriminated on the grounds of her identity (a combination of her ethnicity, her sexual orientation and her gender) would not be afforded legal protection on the multiple grounds, nor would it be recognised that her multiple identities could intersect. Instead, a legal claim for discrimination would need to be argued on every single ground (ethnicity, sexual orientation and gender). As various grounds are subject to different legal regimes, the claim would be very cumbersome, not to mention expensive. Consequently, the claimant would need to decide with the greatest care which ground would have more chance of success before the court. Thus, the legal framework falls short of protecting people's actual identity. Moreover, the framework fails to provide a basis to challenge, and more importantly, to modify or remove harmful stereotypes, 5 ultimately entrenching the compartmentalisation and fragmentation of people's identities.

Although, the EU legal framework remains inadequate in addressing claims of multiple discrimination, it appears nevertheless to be sympathetic to the argument for the protection against multiple discrimination and intersectional disadvantages, mainly under the influence of dynamic academic research. ${ }^{6}$ Whilst the EU legislator is beginning to realise the importance of multiple discrimination, 7 it has not gone far enough and has arguably chosen an overly simplified approach. The proposal for a Council Directive on implementing the principle of equal treatment between persons irrespective of religion or belief, disability, age and sexual orientation, 8 adopted by the European Commission in early 2008 (and still under discussion to date) illustrates the struggles relating to the progressive inclusion of multiple discrimination provisions into the EU legal framework particularly well. This paper contends that despite some breakthroughs, the recent legislative initiative remains unable to genuinely improve the anti-discrimination law.

In order to explore these assumptions, this article is organised in three main parts. The first part of the article analyses the theoretical framework underlying anti-discrimination law in the EU and its relationship to the concepts of multiple discrimination and intersectional disadvantage. The second part of the paper examines the current proposed directive implementing the principle of equal treatment between persons irrespective of religion or belief, disability, age and sexual orientation with a view to critically assess it. In part three, the EU anti-discrimination legal framework is scanned

\footnotetext{
5 B. Smith, 'Not the Baby and the Bathwater: Regulatory Reform for Equality Laws to Address WorkFamily Conflict', Sydney Law Review, Vol. 28, No. 4, 2006, p. 701.

${ }^{6}$ See for instance, D. Schiek and V. Chege (eds.), European Union Non-Discrimination Law: Comparative Perspectives on Multidimensional Equality Law, Abingdon, Routledge-Cavendish, 2008; D. Schiek and A. Lawson (eds.), European Union Non-Discrimination Law and Intersectionality, Farnham: Ashgate, 2011; E. Grabham, D. Cooper, J. Krishnadas and D. Herman (eds.), Intersectionality and Beyond: Law, Power and the Politics of Location, London, Routledge-Cavendish, 2008; L. McCall, 'Managing the Complexity of Intersectionality', Signs: Journal of Women in Culture and Society, Vol. 30, No. 3, 2005, pp. 771-800; A. Phoenix and P. Pattynama (eds.), European Journal of Women's Studies, Special Issue on Intersectionality, Vol. 13, No. 3, 2006.

7 European Commission, Tackling Multiple Discrimination: Policies, Practices and Laws, Brussels: European Commission, 2007(a); European Commission, Conference Proceedings: Equal Opportunities for All - Multiple Discrimination Matters, 6-7 December 2007, Elsinor, Denmark, Brussels: European Commission, 2007(b).

${ }^{8}$ COM (2008) 426 final, 07/02/2008.
} 
for the problems it presents for people experiencing multiple discrimination and intersectional disadvantage.

\section{Theoretical Framework}

Despite a high level of complexity, the EU anti-discrimination and equality legal framework only allows for the redress of an exhaustive number of grounds of discrimination and excludes any form of multiple discrimination claims. The EU framework was built up on the basis of the concept of formal equality. It originates in the Aristotelian doctrine of equality, which states that "things that are alike must be treated alike, while things that are unlike should be treated in proportion to their unalikeness." 9 Although, the concept of equality in EU law has evolved considerably to involve substantial equality, ${ }^{10}$ the need to find a comparator remains central in many cases to the establishment of discrimination. ${ }^{11}$ The problem is that it is nearly impossible, but also impracticable to systematically find a comparator that does share prohibited characteristics with the complainant, especially in cases of multiple discrimination and intersectional disadvantage. ${ }^{12}$ Thus, this construction of equality is flawed as it neglects the diversity that shapes human existence.

So what exactly are multiple discrimination and intersectional disadvantages, and how do they provide a better form of protection for some individuals? In the EU law context, multiple discrimination covers "all instances of discrimination on several grounds contained in [Article 19 TFEU] and in other instruments." 13 Despite the absence of an EU legal definition, ${ }^{14}$ it is accepted that multiple discrimination depicts discrimination against an individual on more than one ground. Multiple discrimination can further be subdivided into two strands; namely, additive and compound discrimination. 15 The former concept describes a situation where a person's identity markers are rooted in two or more different groups and the individual suffers from discrimination as a result. ${ }^{16}$ For example, a coloured skin lesbian might experience discrimination on the basis of her gender in one situation, on the ground of her sexuality in another and because of her ethnicity in yet another. ${ }^{17}$ The latter concept of compound discrimination inflates the discrimination

\footnotetext{
${ }^{9}$ Aristotle, Ethica Nicomachea V. 3 1131a - 1131b (W. Ross trans., 1925).

${ }^{10}$ See for instance Case C-243/95 Hill and Stapleton [1998] ECR I-3739.

${ }^{11}$ Direct discrimination occurs when "one person is treated less favourably than another is, has been or would be treated in a comparable situation"(Article 2(a) of Council Directive 2000/43/EC); indirect discrimination occurs "where an apparently neutral provision, criterion or practice would put persons having [a racial or ethnic origin,] a particular religion or belief, a particular disability, a particular age, or a particular sexual orientation at a particular disadvantage compared with other persons"(Article 2(b) of Council Directive 2000/43/EC).

${ }^{12}$ G. Moon, 'Multiple Discrimination - Problems Compounded or Solutions Found', Justice Journal, Vol. 3, 2006, pp. 86-102; Kantola and Nousianen, op. cit, p. 466.

${ }_{13}$ S. Burri and D. Schiek (eds.), Multiple Discrimination in EU Law: Opportunities for Legal Responses to Intersectional Gender Discrimination?, Brussels, European Commission, 2009, p. 4.

14 I. Carles and O. Jubany-Baucells (eds.), The Use of Racial Antidiscrimination Laws: Gender and Citizenship in a Multicultural Context, Genderace Report, June 2010, p. 194.

15 These two types of multiple discrimination are well established within the literature; see for instance Schiek and Chege, 2008, op. cit.

${ }^{16} \mathrm{~S}$. Hannett, 'Equality at the Intersections: The Legislative and Judicial Failure to Tackle Multiple Discrimination', Oxford Journal of Legal Studies, Vol. 23, No. 1, 2003, p. 68; E.W. Shoben, 'Compound Discrimination: The Interaction of Race and Sex in Employment Discrimination', New York University Law Review, Vol. 55, 1980, p.794.

17 European Commission, 2007(a), op. cit, at p. 16.
} 
experience. When discrimination occurs on two or more grounds each ground moulds to the next, creating a compounded effect of discrimination. Consequently, it becomes difficult to segregate the components of the discrimination. An example of compounded discrimination can be found in the UK case of Perera $v$ Civil Service Commission (No. 2). ${ }^{18}$ In this case, an employer had set various requirements for applicants for a job with respect to age, experience in the UK, command of the English language and nationality. Mr Perera was not hired because he lacked a combination of the required factors. As a result, he was subjected to a compounded discrimination experience. Therefore, compounded discrimination is a situation where different discriminations merge together although they can still be separated in different grounds.

The concept of intersectional discrimination in which the discrimination experience cannot be disentangled into a single strand of discrimination is similar (because the discrimination is based on more than one ground) but also strikingly different. ,. In instances of intersectional disadvantages, the discriminatory grounds are "routed through one another and... cannot be untangled to reveal a single cause." 19 Intersectional discriminatory grounds interact to form a unique discrimination experience. This is not unique in the sense that it is isolated and rare for this form of discrimination to occur, but rather, an individual suffers discrimination on the basis of her/his own unique identity markers, creating a unique experience. In other words, intersectional discrimination is discrimination based on a specific combination of different aspects, for instance a person is discriminated as a black woman and this is linked to stereotyping.

The pioneer behind the identification of this unique form of discrimination is Kimberlé Crenshaw, who coined the term during her plight for recognition of African American woman's rights in the 1980's. She used the analogy of intersecting streets to describe the effect of the discrimination black women were suffering: 20

"Discrimination, like traffic through an intersection, may flow into one direction and it may flow into another. If an accident happens at an intersection, it can be caused by cars travelling from any number of directions, and sometimes, from all of them. Similarly, if a black woman is harmed because she is in the intersection, her injury could result from sex discrimination or race discrimination."

While traditionally used to describe discrimination on the basis of race and gender, the intersectional methodology can be used to examine any number or

\footnotetext{
${ }^{18}$ Perera $v$ Civil Service Commission (No. 2) [1983] IRLR 166.

19 E. Grabham, 'Introduction' in E. Grabham, D. Cooper, J. Krishnadas and D. Herman (eds.),

Intersectionality and Beyond: Law, Power and the Politics of Location, London, Routledge-Cavendish, 2008, at p. 1.

${ }^{20} \mathrm{~K}$. Crenshaw, 'Demarginalising the Intersection of Race and Sex: a Black Feminist Critique of Antidiscrimination Doctrine, Feminist Theory and Antiracist Politics', University of Chicago Legal Forum, 1989, p. 145.
} 
combination of discriminatory grounds. ${ }^{21}$ The UK case of Bahl $v$ the Law Society ${ }^{22}$ illustrates intersectional disadvantage in the workplace. Ms Bahl, an Asian woman, was the subject of alleged discriminatory treatment on the basis of her race and gender. Neither of which could be isolated as the sole cause of her discriminatory experience; it was the very fact that she was both Asian and a woman that led to the disadvantage. In order to show the effect of the discrimination, the Employment Tribunal allowed Ms Bahl to use a white man as a comparator. Unsurprisingly however, on Appeal, the Tribunal's approach was found to be incorrect. The grounds of gender and race had to be untangled and examined separately.

There is no doubt that courts have struggled to appropriately address discrimination on the basis of more than one ground because intersectionality is not a straight forward concept. ${ }^{23}$ While its origins are found in legal discourse, intersectionality has expanded into interdisciplinary fields, such as gender studies, sociology, political science, economics and cultural studies. ${ }^{24}$ The diversity and complexity of intersectionality mirrors that of the human beings' identity. Thus, the adoption of an interdisciplinary approach is an excellent tool to identify those unidentified victims of multiple discrimination and to understand their experience. Intersectionality "requires us to look beneath the surface and beyond the prevailing norm paradigm that leaves various synergetic vulnerabilities unnoticed in the margins." 25

\section{The Recent EU Legislative Initiatives}

In contrast to other jurisdictions such as the United States, the EU started from the outset to build anti-discrimination law on the ground of sex in the Treaty of Rome. ${ }^{26}$ This was followed by the introduction in the Amsterdam Treaty of a provision giving the EU competence "to take appropriate action to combat discrimination based on sex, racial or ethnic origin, religion or belief, disability, age and sexual orientation." 27 On the basis of this provision, two new anti-discrimination directives were adopted in the early 2000s, with the aim of securing effective legal mechanisms against discrimination on these specific grounds.

Interestingly, both Directives acknowledge multiple discrimination. Directive 2000/43/EC (hereafter the Race Directive) ${ }^{28}$ prohibits racial discrimination

\footnotetext{
${ }^{21}$ R. Neilsen, 'Is EU Equality Law Capable of Addressing Discrimination Yet?', in D. Schiek and V. Chege (eds.), European Union Non-Discrimination Law: Comparative Perspectives on Multidimensional Equality Law, Abingdon, Routledge-Cavendish, 2008, p. 33.

${ }^{22}$ Bahl $v$ the Law Society [2004] IRLR 799.

23 J. Squires, 'Intersecting Inequalities: Reflecting on the Subjects and Objects of Equality', The Political Quarterly, Vol. 79, 2008, p. 55.

24 Burri and Schiek, op. cit. p. 4.

25 O. Arnardóttir, 'Multidimensional Equality from Within: Themes from the European Convention on Human Rights', in D. Schiek and V. Chege (eds.), European Union Non-Discrimination Law:

Comparative Perspectives on Multidimensional Equality Law, Abingdon, Routledge-Cavendish, 2008, p. 55 .

${ }^{26}$ Article 119 of the Treaty of Rome became Article 141 EC with the entry into force of the Amsterdam Treaty, and is now Article 157 TFEU following the adoption of the Treaty of Lisbon.

27 Article 13 EC has been replaced by Article 19 TFEU following the adoption of the Lisbon Treaty.

${ }^{28}$ Council Directive 2000/43/EC of 29 June 2000 implementing the principle of equal treatment between persons irrespective of racial or ethnic origin, OJ $2000 \mathrm{~L} 180 / 22$.
} 
in and outside the workplace as an explicit tool for fighting racism and xenophobia. ${ }^{29}$ Recital 14 in the preamble of the Race Directive recalls that promoting equality between men and women is important "especially since women are often the victims of multiple discrimination." Directive 2000/78/EC (hereafter the Employment Equality Directive) ${ }^{30}$ provides a general framework for equal treatment in employment, occupation and vocational training on the grounds of religion or belief, disability, age or sexual orientation in the workplace. As in the Race Directive, and under similar terms, the Employment Equality Directive expressly recognises multiple discrimination at recital 3 of its preamble. Unfortunately, preambles of directives are not legally binding on the Member States and are therefore not required to be transposed into national law, nor can they be given direct effect. Thus, the acknowledgments in the preamble of both Directives have very limited effect for the legal recognition of multiple discrimination.

The Treaty of Lisbon has further broadened the scope of EU equality and nondiscrimination law by providing constitutional foundations, which could sustain the launch of the concepts of multiple discrimination and intersectionality in the EU legal order. Under Article 10 TFEU the EU has a duty to mainstream equality and non-discrimination in all of its policies and activities. This means that, in addition to gender mainstreaming required by Article 8 TFEU, "in defining and implementing its policies, the Union shall aim to combat discrimination based on sex, racial or ethnic origin, religion or belief, disability, age or sexual orientation." 31 While this is a positive step forward, Article 10 TFEU appears to provide an exhaustive list of discrimination grounds, leaving no room for multiple or intersectional discrimination cases. However, the existence of a non-exhaustive list of prohibited grounds in the Charter (which status has been elevated to Treaty level) might help by-pass this problem. Indeed, although it fails to specifically highlight multiple or intersectional discrimination, the Charter provides scope for these forms of discrimination to be interpreted by way of the nonexhaustive list of prohibited grounds of discrimination. Article 21 specifies that "any discrimination based on any ground such as sex, race, colour, ethnic or social origin, genetic features, language, religion or belief, political or any other opinion, membership of a national minority, property, birth, disability, age or sexual orientation shall be prohibited." Use of the words "such as" provide room for the inclusion of other forms of discrimination (including multiple or intersectional) as the list merely provides examples of forms of discrimination.

The most significant development with regards to the emergence of the concepts of multiple discrimination and intersectional disadvantage, however, is not found in the EU constitutional evolution but in a proposed secondary legislation. Indeed, the European Commission adopted in 2008 a proposal for a Council Directive on the implementation of the principle of equal treatment between persons irrespective of religion or belief, disability, age and sexual

\footnotetext{
29 C. Brown, 'The Race Directive: Towards Equality for All the People of Europe?', Yearbook of European Union Law, Vol. 21, 2002, pp. 196-204.

${ }^{30}$ Council Directive 2000/78/EC of 27 November 2000 establishing a general framework for equal treatment in employment and occupation, OJ $2000 \mathrm{~L} 303 / 16$.

${ }^{31}$ Article 10 TFEU.
} 
orientation (hereafter the proposed anti-discrimination directive outside employment or the proposed directive). ${ }^{2}$ The proposed directive aims to complement the rights contained in the Race and in Employment Equality Directives by prohibiting discrimination on the basis of four grounds of discrimination (religion or belief, disability, age and sexual orientation) outside the labour market. Hence, it proposes to address the shortcomings of the Employment Equality Directive and emulate the wider protection of the Race Directive. The proposed anti-discrimination directive outside employment aims to apply to the public and private sectors in social protection, social advantage, education, access to and supply of goods and services, including housing.

Prima facie, the proposition put forward by the Commission stays firmly in line with both the Race and in the Employment Equality Directives and does not assist in reforming the existing EU anti-discrimination legal framework. 33 As in the Race and the Employment Equality Directives, the proposed directive acknowledges in its preamble the importance of multiple discrimination, but falls short of providing legal substance to this concept. In addition, it does not make any reference to intersectional disadvantages. This is particularly disappointing because at the time of the proposal's adoption, multiple discrimination and intersectionality had been on the "reflection table" of the Commission. 34

The explanatory memorandum of the proposed directive suggested the Commission was ready to expand multiple discrimination and intersectionality into EU policy and beyond the scope of the directive. It even edged towards placing an onus on Member States to address multiple discrimination in their own national legislation. 35 While it is unclear why the Commission never followed through, Bell suggests that it may have been to limit contentious issues that might arise during negotiations, thus slowing the adoption of the directive. The proposed directive was the perfect opportunity to push the boundaries of the existing legal framework, as "a directive dealing simultaneously with four grounds of discrimination seems entirely apt for addressing the question of multiple discrimination." 36 The failings of the proposed directive therefore represent a missed opportunity to address multiple and intersectional discrimination, the problems associated with finding an appropriate comparator and remedies for discrimination on multiple grounds. 37

\footnotetext{
${ }^{32}$ Op. cit. N. 8. At the time of writing, it is not clear when or whether the proposed anti-discrimination directive outside employment will be adopted, as the 27 EU Member States appear to be unable to reach unanimous agreement.

33 M. Bell, 'Advancing EU Anti-Discrimination Law: the European Commission's 2008 Proposal for a New Directive', The Equal Rights Review, Vol. 3, 2009, p. 8.

34 See European Commission, 2007(a), op.cit. N. 7 and European Commission, 2007(b), op.cit. N. 7.

35 Op. cit. N. 8, explanatory memorandum at p. 5 "Attention was also drawn to the need to tackle multiple discrimination, for example by defining it as discrimination and by providing effective remedies. These issues go beyond the scope of this Directive but nothing prevents Member States taking action in these areas."

${ }^{36}$ Bell, op. cit. p. 9.

37 Ibid.
} 
Nevertheless, on a more positive note, the European Parliament has suggested a number of liberal amendments to the proposed directive, $3^{8}$ which are no doubt influenced by academic thinking on multiple discrimination and intersectionality. The Parliament proposed the inclusion of the following definition of multiple discrimination in Article 1:39

Multiple discrimination occurs when discrimination is based:

(a) on any combination of the grounds of religion or belief, disability, age, or sexual orientation, or

(b) on any one or more of the grounds set out in paragraph 1, and also on the ground of any one or more of

(i) sex (in so far as the matter complained of is within the material scope of Directive 2004/113/EC as well as of this Directive),

(ii) racial or ethnic origin (in so far as the matter complained of is within the material scope of Directive 2000/43/EC as well as of this Directive), or

(iii) nationality (in so far as the matter complained of is within the scope of Article 12 of the EC Treaty).

In this Directive, multiple discrimination and multiple grounds shall be construed accordingly.

This is a positive step forward, because for the first time multiple discrimination has a chance to become legally binding under EU law. However, the definition recommended by the Parliament is not without its flaws, as it fails to recognise intersectionality and implies instead a notion of additive or compound discrimination. Further, the European Parliament's suggestion that the preamble of the proposed directive be amended to "include direct and indirect discrimination, multiple discrimination, harassment, instructions to discriminate and denial or reasonable accommodation" 40 neglects intersectional discrimination and may entice serious misinterpretations. Should a court be faced with intersectional discrimination, it may decide that this form of disadvantage not fall under the umbrella of multiple discrimination, because it is impossible to disentangle multiple discrimination into separate strands in cases of intersectional disadvantage.

Furthermore, a potential backlash could be created by European Parliament's initiative. As the scope of the proposed directive only extends to four grounds of discrimination outside the field of employment, any express prohibition of multiple discrimination in the proposed directive could lead to the assumption that the lack of an express provision in any of the other antidiscrimination directives is intentional.41 This would mean that directives which lack an express provision on multiple discrimination or

\footnotetext{
${ }^{38}$ European Parliament legislative resolution of 2 April 2009 on the proposal for a Council directive on implementing the principle of equal treatment between person irrespective of religion or belief, disability, age or sexual orientation, $\operatorname{COM}(2008) 0426$ - C6-0291/2008-2008/0140(CNS).

39 Ibid., Amendment 37.

40 Ibid., Amendment 16.

${ }^{41}$ D. Schiek and J. Mulder, 'Intersectionality in EU Law: A Critical Re-Appraisal” in D. Schiek and A. Lawson (eds.), European Union Non-Discrimination Law and Intersectionality, Farnham, Ashgate, 2011, pp. 259-273.
} 
intersectionality could be interpreted as excluding these concepts a contrario. As courts have begun to recognise multiple discrimination in some Member States, further confusion and fragmentation might result from this interpretation.

Moreover, this legal development poses a real risk for women because if the proposed directive is to be adopted (either as is, or with the European Parliaments suggested amendments) gender discrimination will become the least protected ground under EU law. 42 This is particularly a problem as sex discrimination is still not prohibited in the areas such as education and the media in contrast to the Race Equality Directive, which has a much wider scope than the gender equality legislation. By failing to appropriately address multiple discrimination and intersectionality, the proposed directive reinforces the hierarchy of the EU anti-discrimination framework, where women are at the bottom. This means that subsets of women (for example, disabled women or coloured skin women) are not provided with adequate protection. While the current anti-discrimination framework has greatly advanced since the Treaty of Amsterdam, the structure of the directives arguably perpetuates injustice and causes conflict between the many groups advocating for different inequalities. 43 The proposed directive prohibiting discrimination on the basis of sexual orientation disability, age and religion or belief, is likely to further impact this hierarchy and keep equality rights for women at the bottom as it promises more protection for these grounds than that of gender.

\section{Critical Analysis of the Recent EU Legal Developments and Future Perspectives for Intersectional Disadvantage}

The EU anti-discrimination legal framework appears to be standing at a crossroad. The choice made by the Commission and the European Parliament to promote, albeit with some restriction, the concept of multiple discrimination over that of the protection of intersectional disadvantage has profound consequences for the EU anti-discrimination legal framework as a whole. Should the proposed anti-discrimination directive outside employment be adopted, it would define the future direction for the protection of all individuals against discrimination in the EU. Indeed, the amendments put forward by the European Parliament to the proposed directive, although forward thinking because they introduce legally binding obligation towards multiple discrimination, remain largely inadequate to address the reality of many people's discrimination experience. Introducing a concept of multiple (compounded) discrimination to the proposed directive may be attractive because the concept is relatively simple and clear. Nevertheless many problems are linked to adopting such a rigid option.44 A legal framework, which includes multiple discrimination should be based on a single antidiscrimination procedure in which all axes of discrimination are similarly

\footnotetext{
$4^{2}$ Bell, op. cit. p. 9.

43 E. Lombardo and M. Verloo, 'Institutionalising Intersectionality in the European Union: Policy Developments and Contestations', International Feminist Journal of Politics, Vol. 11, No. 4, 2009, p. 482.

44 Kantola and Nousianen, op. cit. N. 2, at p. 468.
} 
weighted and addressed. 45 However, the reality could not be further from this ideal. Indeed, members of various groups face widely different struggles as illustrated by the distinctive pleas between, on the one hand people discriminated on the grounds of sexual orientation who strive for recognition and equal access to the matrimonial rights and, on the other hand, individuals facing race or sex discrimination who are heavily interested in implementing equal pay and equal treatment in the workplace. ${ }^{46}$ Moreover, inequalities are multifaceted and often fluid, because individuals' identities are multiple and evolving. People can choose their religion; they might choose to display or keep hidden their beliefs, however, gender, age or race are for most people permanent and cannot usually be concealed. 47 In contrast to a rigid system of multiple discrimination, a legal framework which allow for the redress of intersectional disadvantage "disrupts established group demarcations used in anti-discrimination law." 48 Therefore, if one is "to assume that groups are rigidly delineated by race, gender, disability, sexual orientation or other status, [then one] is to render invisible those that are found in the intersection between those groups." 49

Additive or compounded multiple approaches further galvanise the compartmentalisation of individuals' identity. In doing so, a framework of multiple discrimination risks setting minority groups to work against one another, instead of fostering cooperation and synergy. $5^{\circ}$ This often results in hierarchy of inequality, the so-called "oppression Olympics", which put the different groups in competition against one another in the hope of winning the main political support to create momentum on policy remedies for that particular group. ${ }^{51}$

All the arguments point toward using an intersectional approach as a way to tackle the shortcomings of the concept of multiple discrimination. At least two large advantages can be identified from adopting an intersectional approach. 52 In the first instance, an intersectional analysis provides grounds to understand various discrimination experiences and in doing so, it allows discriminations which have remained hidden and unnoticed under previous anti-discrimination approaches to be disclosed and revealed. This challenges society's persistent and enduring inequitable structures. This process is very similar to that which was introduced following the adoption of the concept of indirect discrimination in EU law. Rules, requirements, organisation of general society, can at first glance appear to be fair, but the use of adequate legal tools (be it indirect discrimination or through the use of intersectional

\footnotetext{
45 Ibid., at p. 468.

${ }^{46}$ M. Verloo, 'Multiple Inequalities, Intersectionality and the European Union', European Journal of Women's Studies, Vol. 13, No. 3, 2006, p. 221.

47 Kantola and Nousianen, op. cit., p. 468.

${ }^{48}$ Fredman, op. cit., p. 73 .

49 Ibid.

$5^{\circ}$ A.-M. Hancock, 'When Multiplication Doesn't Equal Quick Addition: Examining Intersectionality as a

Research Paradigm', Perspectives on Politics, Vol. 5, No. 1, 2007, p. 68.

${ }^{51}$ Ibid. See also S. Mazey, 'Policy Entrepreneurship, Group Mobilisation and the Creation of a New Policy Domain: Women's Rights and the European Union', in J. Richardson (ed.), Constructing a

Policy-Making State? Policy Dynamics in the European Union, Oxford, Oxford University Press, 2012. $5^{2} \mathrm{~T}$. Makkonen, 'Multiple, Compound and Intersectional Discrimination: Bringing the Experiences of the Most Marginalized to the Fore', Institute for Human Rights, 2002,

<http://web.abo.fi/instut/imr/norfa/timo.pdf $>$, accessed on $10^{\text {th }}$ January 2012, , p. 36.
} 
discrimination) can help to reveal, combat and ultimately redress previously hidden structural discrimination. In practical terms, intersectional analysis would allow harmful stereotyping, which until now has remained hidden, to be revealed and tackled. Such prejudices include the promiscuity of Asian women;53 the high absenteeism amongst foreign female workers with dependent children; 54 or the doubt that lesbians could not possibly also be good mothers.55 At the moment all of these examples and more can only be dealt with through the European Convention of Human Right or the Convention on the Elimination of All Forms of Discrimination against Women (CEDAW), which are relatively weaker legal enforcement procedures compared to that of the EU via the direct effect principles and the ability for individual to claim EU rights directly into their domestic courts. In addition to this, enhancing the understanding of an intersectional analysis of discrimination will result in a more encompassing and effective policies to combat all forms of discrimination, including those that result from intersectional disadvantages. In other words, the use of an intersectional approach would allow the reform and re-shaping of existing antidiscrimination legal frameworks which could be applied to the largest section of population, in ways that multiple discrimination could not reach.

Finally, a point must be made with regards to the EU's obligation to lead such a reform of the anti-discrimination legal framework. As explained in the introduction, the EU is based on the values of equality and antidiscrimination, which form the fundamental principle of democracy. It is therefore a fundamental obligation for the EU to take the lead in implementing equality and anti- discrimination law which can be applied across the Member States. Despite some recognition of the potential of the concept of multiple discrimination and intersectional disadvantages, 56 the EU's engagement with both concepts has been very limited. As "intersectional policies have no institutional champions at the moment, and no machinery to drive the efforts of such development", 57 the EU still falls shorts of redressing multiple and intersectional disadvantages. The inclusion of the European Parliament's amendments in the limited scope of the proposed directive would only partially obligate the EU any further. The lack of any legally binding instruments at EU level means that neither the multiple discrimination nor the intersectional approach to anti-discrimination have managed to filter through to legal practice. There is an overall absence of knowledge and awareness regarding these legal concepts both at the EU and national levels. In addition, there is a critical lack of statistical evidence, 58 which means that the current legal framework is likely to be unable to be amended in any substantial way.

\footnotetext{
53 S. K. Choo, 'Converging Stereotypes in Racialized Sexual Harassment: Where the Model Minority Meets Suzie Wong', Journal of Gender Race and Justice, Issue 1, 1997 pp. 177-212.

54 Yilmaz-Dogan v. The Netherlands, CERD, Communication No. 1/1984, UN Doc.

CERD/C/36/D/1/1984 (1988) (Race Committee).

55 E.B. v. France, Appl. No. 43546/02, Jan. 22, 2008, at para. 96-98 (European Court of Human Rights).

${ }^{56}$ For example, the European Commission's sponsored report on Tackling Discrimination; see European Commission, 2007a, op. cit.

57 Lombardo and Verloo, op. cit., p. 482.

${ }^{8}$ Burri and Schiek, op. cit., p. 18.
} 
Moreover, the Member States have generally resisted the introduction of multiple discrimination in their national anti-discrimination legal system, 59 as previously illustrated in the UK case of Bahl $v$ the Law Society. ${ }^{60}$ Evidence shows that in the rare occasions where Member States have addressed multiple and intersectional discrimination, the results have been biased, ${ }^{61}$ disparate, ${ }^{62}$ not legally binding, ${ }^{63}$ incomplete and in need of further legal development 64 or simply underfunded.65 The EU can learn from these national experiences by providing a complete definition of intersectional disadvantage and thereon clearly prohibit these kinds of discrimination, with adequate legal tools and properly funded awareness campaigns. Thus, EU leadership in this area is crucial. EU legally binding instruments must provide the adequate momentum for the Member States to act decisively and harmoniously on multiple discrimination and intersectional disadvantage. Reference to the concept of multiple discrimination in the preamble of EU directives is not enough as illustrated by the transposition of both the Race and the Employment Equality Directives, which has led to marginal implementation of the concept at national level. In 2007, a review of Member State legislation, carried out by the European Network of Legal Experts, has demonstrated that only five countries (Austria, Germany, Poland, Romania and Italy) out of the 27 EU Member States have addressed multiple discrimination in their national legislation. ${ }^{66}$ Without an EU Directive specifically designed to define the concepts in order to provide Member States with both methodological guidance and coherence, the incorporation of the concepts of multiple discrimination or intersectionality into national law will continue to pose problem. Without a comprehensible and harmonised legal obligation, Member States risk developing very different legal instruments incompatible with one another, resulting in variable national levels of protection. ${ }^{67}$ Some Member States might also decide to completely ignore these concepts. In the end, such a lack of harmonisation would further confuse citizens. Ultimately, rights that are unclear are useless for individuals' protection.

\section{Conclusions}

The above analysis has highlighted some of the flaws in the current EU antidiscrimination framework and the proposed anti-discrimination directive outside employment. In some instances with regard to the European Parliaments' suggested amendments and their possible future judicial

\footnotetext{
59 I. Carles, E. Howard and E. Kofman, 'Gendered Experiences of Racial Discrimination: Comparative Socio-Legal Research', in D. Schiek and A. Lawson (eds.), European Union Non-Discrimination Law and Intersectionality, Farnham, Ashgate, 2011, pp. 227-240.

60 Op.cit. N. 22.

${ }^{61}$ A. I. Aybars, 'Women with Disability in Turkey and France', in D. Schiek and A. Lawson (eds.), European Union Non-Discrimination Law and Intersectionality, Farnham: Ashgate, 2011, pp. 79-96. 62 Ibid.; Carles, Howard and Kofman, op. cit.

${ }^{6}$ S. Burri, 'Promises of an Intersectional Approach in Practice? The Dutch Equal Treatment Commission's Case Law', in D. Schiek and A. Lawson (eds.), European Union Non-Discrimination Law and Intersectionality, Farnham, Ashgate, 2011, pp. 97-110.

64 G. Moon, 'Justice for the Whole Person: The UK's Partial Success Story', in D. Schiek and A. Lawson (eds.), European Union Non-Discrimination Law and Intersectionality, Farnham, Ashgate, 2011, pp. 157-173.

65 Aybars, op. cit.

${ }^{66}$ Burri and Schiek, op. cit N. 13, at 17; Carles, Howard and Kofman, op. cit.

${ }_{7}$ Carles, Howard and Kofman, op. cit.
} 
interpretation the analysis is hypothetical. Nevertheless, these criticisms prove that drafting legislation that will adequately address multiple discrimination and intersectionality is not an easy task. The European Parliament is credited for its efforts in trying to bring multiple discrimination to the attention of the Commission and the public at large. However, the risks related to the proposed Parliament's amendments outlined above should not constitute an excuse for inaction and thus entrenchment into an even less adequate legal system. It is undeniable that, in its current form, the proposed directive merely fills a few gaps in the existing framework and is a missed opportunity to legislate a modern, unique and complex directive addressing multiple discrimination and intersectionality. It is particularly disappointing this did not happen given the false hope raised by the legal evolution and academic dynamism leading up to the adoption of the proposed directive. Instead, the result is an "increasing disjunction between [...] the array of EU policy initiatives seeking to advance equality via positive action, mainstreaming and data collection, and [...] the actual content of EU legislation which remains wedded to traditional complaints based antidiscrimination model." 68

${ }^{68}$ Fredman, op. cit., p. 16. 